\title{
Decadal Change of the Western North Pacific Summer Monsoon Break around 2002/03
}

\author{
KE XU AND RIYU LU \\ State Key Laboratory of Numerical Modeling for Atmospheric Sciences and Geophysical Fluid Dynamics, \\ Institute of Atmospheric Physics, Chinese Academy of Sciences, Beijing, China
}

(Manuscript received 12 October 2016, in final form 18 September 2017)

\begin{abstract}
A significant decadal change is detected in the break of the western North Pacific summer monsoon (WNPSM) around 2002/03. For the period 1979-2002, the monsoon break occurs in early August, accompanied by noticeable convection suppression over the ocean to the east of the Mariana Islands $\left(10^{\circ}-20^{\circ} \mathrm{N}\right.$, $140^{\circ}-160^{\circ} \mathrm{E}$ ). However, for the period $2003-11$, the monsoon break there is delayed until mid-August. This decadal change is attributable to the differences in the evolution of the WNPSM. Over this break region, convection becomes weaker after its peak in late July for the former period, and the monsoon break appears in early August. In contrast, for the latter period, convection continues strengthening in late July and reaches its peak in early August, and the monsoon break is delayed until mid-August. The differences in the evolution of sea surface temperature (SST) in the western Pacific warm pool region are responsible for the decadal change in the evolution of the WNPSM. In contrast to the former period, for the latter period the southern extent of the warm pool is remarkably warmed, and tends to be higher than the northern extent in mid- and late July, which enhances atmospheric convection nearby but inhibits the development of convection over the northern extent through a local meridional circulation. As the SST in the northern extent continues warming and becomes higher than that in the southern extent, the convection over the northern extent reaches its maximum intensification in early August. The presented results highlight that the spatial pattern of SST changes can modulate the subseasonal evolution of the WNPSM.
\end{abstract}

\section{Introduction}

The monsoon break is a typical phenomenon during monsoon evolution and represents the extent of intraseasonal variability of the monsoon rainfall. The existence of the monsoon break is well known in the South Asian summer monsoon (Krishnan et al. 2000; Goswami and Ajayamohan 2001; Annamalai and Slingo 2001; Gadgil and Joseph 2003; Rajeevan et al. 2010; Singh 2013), but it has not been widely studied for other monsoons.

Recently, a distinct break of the western North Pacific summer monsoon (WNPSM) was identified (Xu and $\mathrm{Lu}$ 2015). This monsoon break occurs climatologically in early August (3-8 August) over the ocean to the east of the Mariana Islands. It is subsequent to the monsoon onset in late July, and is followed by a second rainfall enhancement in mid-August. Between these two rainfall peaks, the monsoon break is characterized by drastically reduced rainfall, suppressed convection, and a weakened monsoon trough. This break of the WNPSM shows a strong year-to-year variation in both intensity

Corresponding author: Riyu Lu, lr@mail.iap.ac.cn and timing. In particular, for about $30 \%$ of years, the monsoon break in early August is very prominent and can feature a precipitation amount that is even less than that before the onset of the monsoon. In a further $30 \%$ of years, the rainfall reduction appears in mid-August, and the related subseasonal evolution tends to be out of phase with the climatology.

$\mathrm{Xu}$ and $\mathrm{Lu}$ (2015) also noted that their monsoon break index, which they used to measure the phase difference in the monsoon break between individual years and the climatology, shows a decreasing trend from the early 2000s onward, using observational outgoing longwave radiation (OLR) beginning in 1979. However, their study focused on the climatological features and interannual variation of the monsoon break, ignoring the decadal signal. It is important to ask, therefore, whether this decadal change in the phase of the monsoon break is statistically significant. If it is, we will have evidence for multiscale interactions over the western North Pacific (WNP) involving seasonal evolution, subseasonal variation, and decadal-scale change, which will help improve our understanding and prediction of the variability of the WNPSM. 
The characteristics of the monsoon break-namely, convection suppression sandwiched between two convection enhancements-reveal a tight connection between the monsoon break and the subseasonal phase evolution of the WNPSM (Xu and Lu 2015). In particular, the convection enhancement prior to the monsoon break is associated with the onset of the WNPSM, and this has been termed the "convection jump" by some researchers (Ueda and Yasunari 1996; Lu et al. 2007; Ueda et al. 2009; Zhou et al. 2016). Therefore, it is speculated that if the monsoon break undergoes a decadal change, it may be related to the differences in the subseasonal phase evolution of the WNPSM. In particular, the differences in convection enhancement before the monsoon break should be noted.

During boreal summer, there are close relationships between convection and SST on the subseasonal time scale in the WNP region (e.g., Arakawa and Kitoh 2004; Wu et al. 2008; Wu 2010; Ye and Wu 2015). The subseasonal variation of SST may affect convection through gradually modifying the surface air temperature, humidity, and thus atmospheric instability, leading to a time lag of convection behind SST of about 1-2 pentads. Therefore, the speculated decadal change in the subseasonal evolution of convection associated with the monsoon break may be influenced by the changes in SSTs.

In summary, the objectives of this study are to explore the decadal change in the WNPSM break in the early 2000s, and to discuss the possible underlying mechanisms. Following this introduction, the data and methods are described in section 2. In section 3 , the significance of the decadal change in the WNPSM break in the early 2000s is examined first, and then the different characteristics of the evolution of convection between the former and latter periods are shown. In section 4 , the influence of subseasonal SST variation on this decadal change is investigated. Conclusions are drawn in the final section.

\section{Data and methodology}

The daily OLR data are from the National Oceanic and Atmospheric Administration (NOAA) satellites: interpolated OLR data (Liebmann and Smith 1996; https:// www.esrl.noaa.gov/psd/data/gridded/data.interp_OLR. html) are used for the period 1979-2013 and uninterpolated OLR data for 2014 (https://www.esrl.noaa.gov/psd/data/ gridded/data.uninterp_OLR.html). The daily horizontal wind, vertical pressure velocity, and relative humidity at multiple pressure levels are from the National Centers for Environmental Prediction (NCEP)-U.S. Department of Energy (DOE) Reanalysis 2 dataset (Kanamitsu et al. 2002), for the period 1979-2014. These data have a horizontal resolution of $2.5^{\circ} \times 2.5^{\circ}$. The daily mean SSTs at high resolution $\left(0.25^{\circ} \times 0.25^{\circ}\right)$ are from the NOAA Optimum Interpolation SST datasets (Reynolds et al. 2007), extending from 1982 to 2014.

Following $\mathrm{Xu}$ and $\mathrm{Lu}$ (2015), who also focused on the WNPSM break, this study begins with a discussion on the decadal change in the break, and then extends into a discussion on the subseasonal evolution of the WNPSM. The monsoon break index used in this study is identical to that used by $\mathrm{Xu}$ and $\mathrm{Lu}$ (2015), which is defined based on the features of climatological convection evolution around the monsoon break:

$$
\begin{aligned}
\operatorname{Index}(i)= & \operatorname{OLR}(i, \text { stage } 2)-0.5[\operatorname{OLR}(i, \text { stage } 1) \\
& +\operatorname{OLR}(i, \text { stage } 3)],
\end{aligned}
$$

where stage 2 includes 3-8 August (around pentad 44), when the climatological WNPSM break occurs. Stage 1 (24 July-2 August; pentads 42 and 43, approximately) and stage 3 (9-18 August; pentads 45 and 46) represent the first enhancement of convection (just after the monsoon onset) and the second enhancement, respectively. The values of OLR are averaged over $10^{\circ}-20^{\circ} \mathrm{N}$, $140^{\circ}-160^{\circ} \mathrm{E}$ - namely, the key region of the monsoon break (Xu and $\mathrm{Lu} 2015)$ - and $i$ means the $i$ th year, starting from 1979. A positive (negative) index value indicates that convection becomes suppressed (enhanced) in early August compared with the previous and subsequent periods, and thus the monsoon break in that particular year is expected to be in phase (out of phase) with the climatological monsoon break.

To examine the decadal phase change of the WNPSM, a $k$-means cluster analysis is performed on the subseasonal evolution of convection over the key region (Wilks 2006, 559-560; Christiansen 2007; Johnson and Feldstein 2010). The convection evolutions over the entire research period are separated into two clusters, and the initial two cluster centers are chosen as the mean convection evolutions for 1979-2002 and 2003-11, respectively. A particular year is allocated to one cluster when the convection evolution in that year is closer to that cluster center than the other, which is determined by comparing the sum of squared differences from the two centers. The center of each cluster is then recalculated as the average of the years belonging to it. This process is repeated until the sum of squared differences for the two clusters cannot be further decreased. The algorithm derives a partition such that the years within each cluster share similar evolution features, which are very different from those of the other cluster.

\section{Decadal change in the WNPSM break}

Figure 1 shows the time series of the monsoon break index. The monsoon break index shows a notable 
(a) Monsoon break index

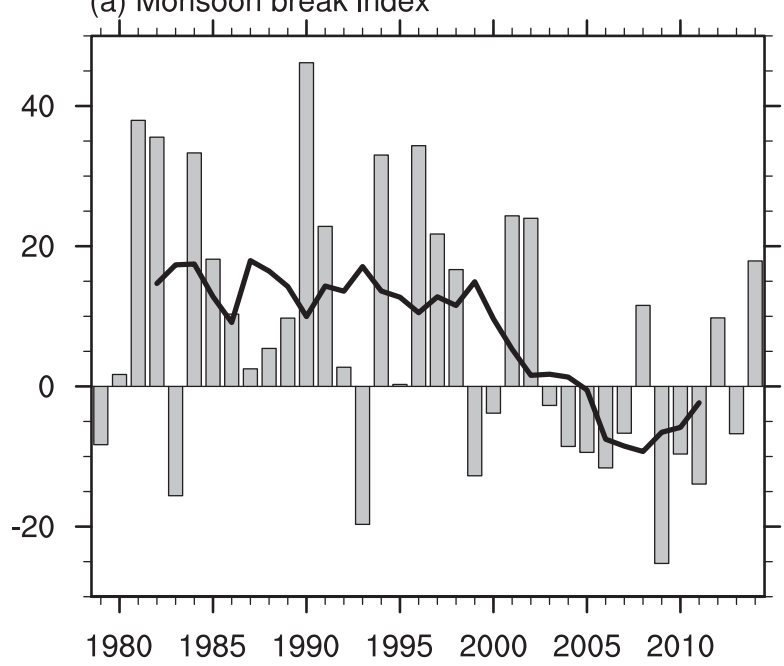

(b) Moving t-test window $=7$

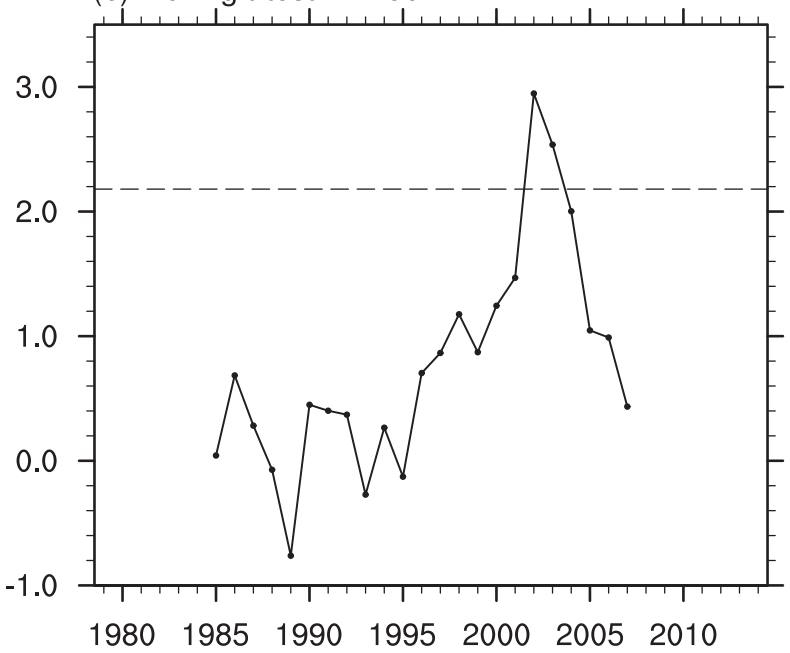

FIG. 1. (a) Time series of the original (bars) and 7-yr running mean (thick line) monsoon break index $\left(\mathrm{W} \mathrm{m}^{-2}\right)$. (b) Moving $t$ values for the changes in the monsoon break index between the preceding and subsequent 7 years. The dashed straight line represents the $95 \%$ confidence level.

decrease beginning in the early 2000s. Specifically, there are only 5 negative years before 2002 out of 24 years, but 9 out of 12 years after 2002 are negative. The 7 -yr running mean index is about $15 \mathrm{~W} \mathrm{~m}^{-2}$ from the 1980 s to the early 2000s, and then becomes negative, with the lowest value being about $-10 \mathrm{~W} \mathrm{~m}^{-2}$. This decadal change of the monsoon break index indicates that the monsoon break is expected to turn from being in phase to out of phase with the climatological monsoon break around the early 2000s.

This decadal change in the monsoon break is further tested using the moving Student's $t$ test with a 7-yr sliding window (Fig. 1b). For instance, the $t$ value in 1990 estimates the extent of differences between 1984-90 and
1991-97. The most significant abrupt point occurs in the year 2002, indicating that the decadal change in the monsoon break happens in 2002/03. This is consistent with the previous analyses (Fig. 1a). In addition, slight adjustments of the sliding window do not change the abrupt point. To further verify whether this decadal change is abrupt or gradual, the variance is calculated after subtracting, respectively, the two epochal means and the 7-yr running mean from the original index. It is found that the epochal means can remove more variance, which suggests that the decadal change at 2002/03 seems more likely to be an abrupt one. Therefore, the study period is divided into two separate periods: 19792002 and 2003-11. The average of the monsoon break index for $1979-2002$ and $2003-11$ is 13.4 and $-8.5 \mathrm{~W} \mathrm{~m}^{-2}$, respectively. This decadal difference is significant at the $99 \%$ confidence level. Additionally, considering that the monsoon break index in the year 2009 is extremely negative, which may have a large influence on the epochal mean, the analyses are also repeated after removing the year 2009 (figures not shown). In doing so, we find that the decadal difference is still significant at the $99 \%$ confidence level.

Figure 2 shows the spatial distribution of OLR from late July to mid-August (pentads 41-46) for the periods 1979-2002 and 2003-11. For the former period (Figs. 2a-f), at pentad 41 , the strong convection, represented by values less than $220 \mathrm{~W} \mathrm{~m}^{-2}$, shows a zonally elongated band extending from the South China Sea (SCS) to the central Pacific along $10^{\circ} \mathrm{N}$. At pentad 42 , the convection over the key region is notably enhanced, and thus leads to a northeastward extension of the strong convection band. The contour of $220 \mathrm{~W} \mathrm{~m}^{-2}$ almost covers the entire key region. This phenomenon has been well documented in previous studies and is referred to as the convection jump (Ueda et al. 1995; Ueda and Yasunari 1996; Wu 2002). Subsequently, the convection over the key region becomes weak from pentad 43 , which is illustrated by the westward shift of the $220 \mathrm{~W} \mathrm{~m}^{-2}$ contour. At pentad 44, the convection over the key region is significantly suppressed, suggesting the occurrence of a monsoon break. At pentads 45 and 46, the convection becomes enhanced again over the key region. The above convection evolution is generally consistent with that in the climatology (1979-2012) shown in Xu and $\mathrm{Lu}$ (2015), which is due to the majority of their analysis period ( $34 \mathrm{yr})$ falling within the former period $(23 \mathrm{yr}$ ) of our study.

For the period 2003-11 (Figs. 2g-1), the distribution of convection at pentad 41 is similar to that for the period 1979-2002. The convection over the key region begins to enhance but remains weak at pentad 42 , when the convection is completely developed for the former period. Convection becomes notably enhanced over the key 
1979-2002

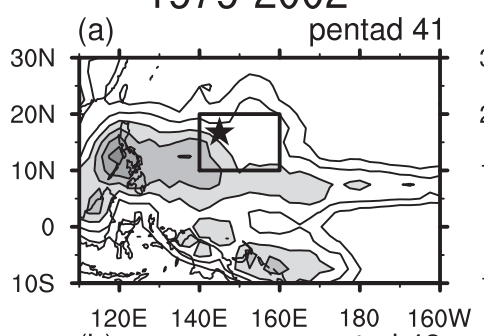

(b) pentad 42
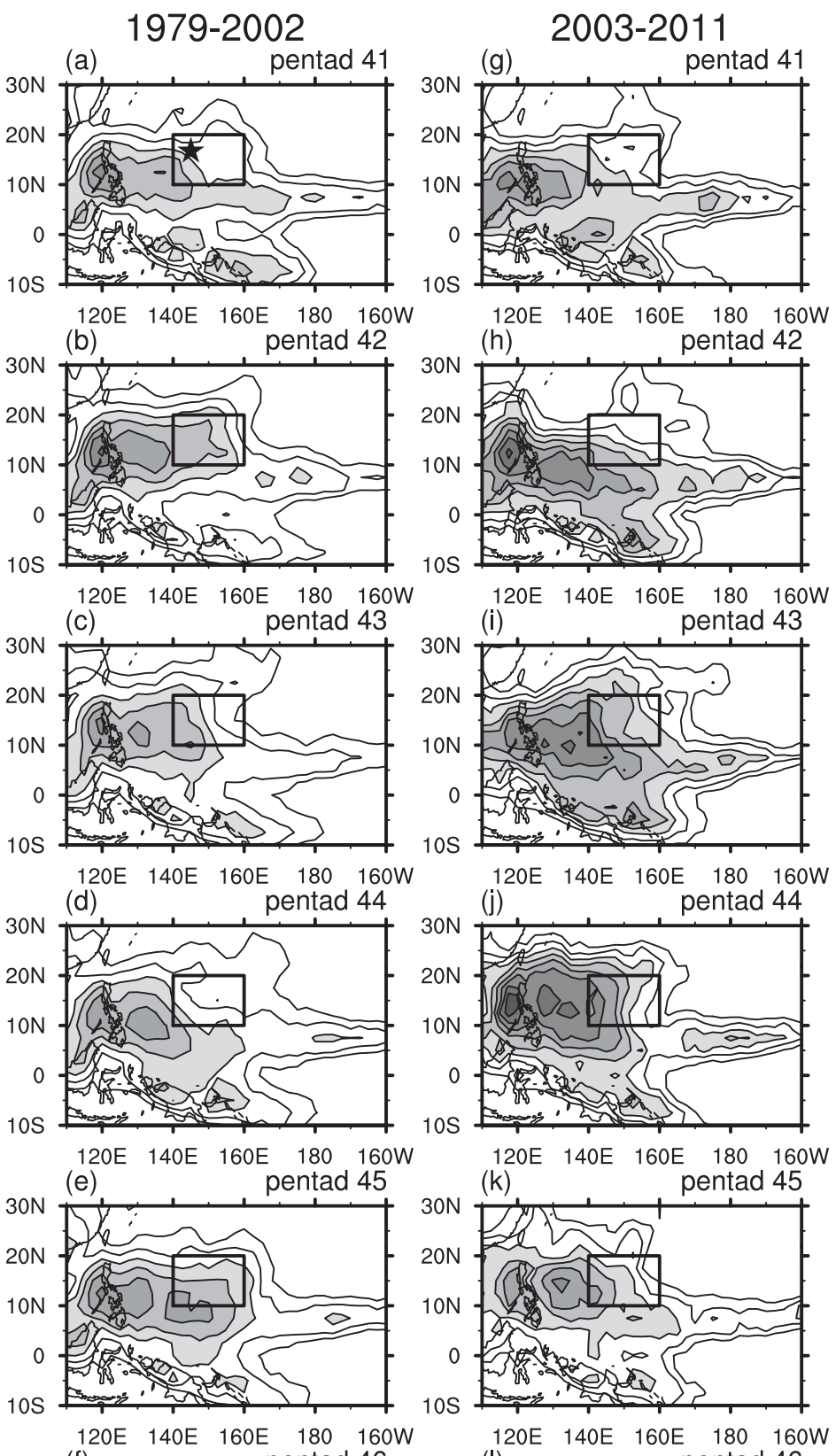

(k)
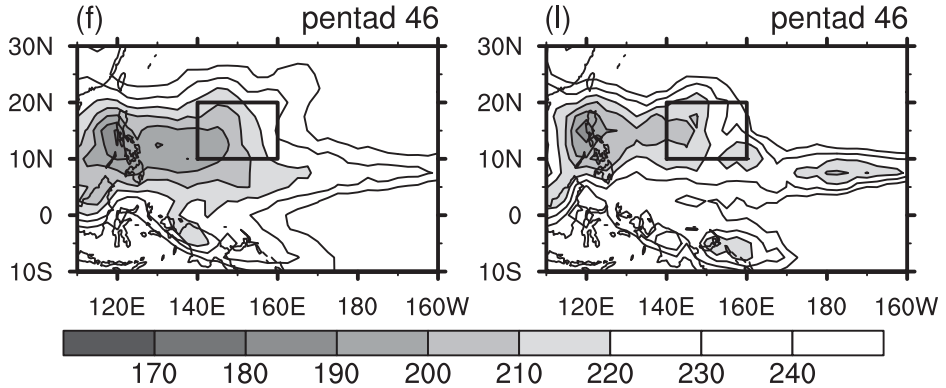

FIG. 2. Spatial distributions of OLR $\left(<240 \mathrm{~W} \mathrm{~m}^{-2}\right)$ during pentads $41-46$ for the periods (a)-(f) 1979-2002 and (g)-(l) 2003-11. The contour interval is $10 \mathrm{~W} \mathrm{~m}^{-2}$, and shading denotes values less than $220 \mathrm{~W} \mathrm{~m}^{-2}$. Boxes mark the key region $10^{\circ}-20^{\circ} \mathrm{N}, 140^{\circ}-160^{\circ} \mathrm{E}$, and the star in (a) indicates the Mariana Islands. 
(a) $1979-2002$

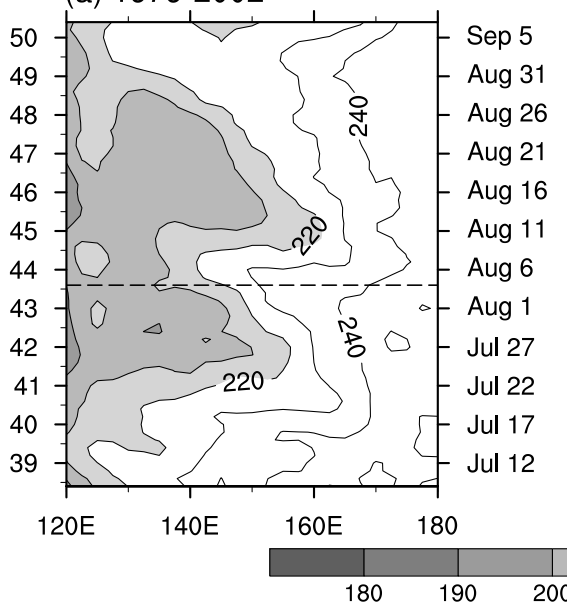

(b) 2003-2011

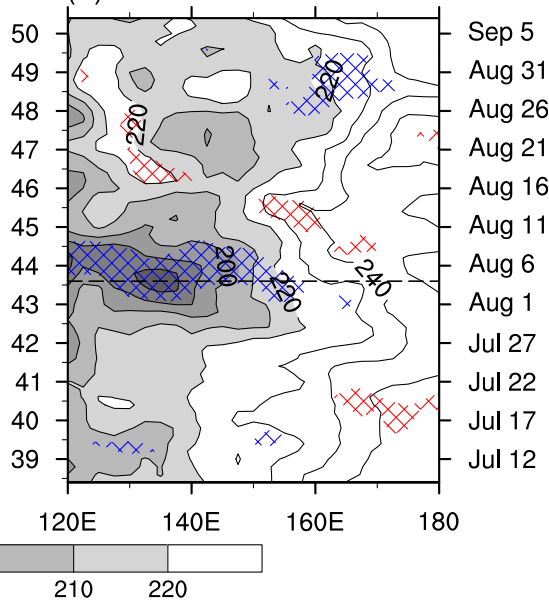

FIG. 3. Longitude-time cross section of the 5-day running mean OLR averaged between $10^{\circ}$ and $20^{\circ} \mathrm{N}$ for the periods (a) $1979-2002$ and (b) 2003-11. The contour interval is $10 \mathrm{~W} \mathrm{~m}^{-2}$, and shading denotes values less than $220 \mathrm{~W} \mathrm{~m}^{-2}$. The red (blue) marked areas in (b) indicate that the positive (negative) differences between 2003-11 and 1979-2002 reach the $90 \%$ confidence level based on the Student's $t$ test. The labels on the left ordinates represent pentads and those on the right represent the middle date of each pentad. The dashed lines indicate 4 August.

region until pentads 43 and 44 . Then, the convection tends to weaken over the key region at pentads 45 and 46 as the monsoon break appears. These results suggest that for the latter period, the convection evolution, including the convection enhancement and subsequent monsoon break, lags by about 1-2 pentads in comparison with the former period.

Figure 3 shows a longitude-time cross section of OLR averaged between $10^{\circ}$ and $20^{\circ} \mathrm{N}$ for the periods 1979 2002 and 2003-11. The averages over these latitudes represent well the characteristics of convection evolution around the monsoon break. For the period 19792002 (Fig. 3a), strong convection $\left(<220 \mathrm{~W} \mathrm{~m}^{-2}\right)$ extends eastward from $140^{\circ} \mathrm{E}$ to about $160^{\circ} \mathrm{E}$ and quickly reaches its peak in late July (pentads 41 and 42). In early August (pentads 43 and 44), the monsoon break occurs, accompanied by significant convection suppression along $140^{\circ}-160^{\circ} \mathrm{E}$, indicated by a notable westward shift of the $220 \mathrm{~W} \mathrm{~m}^{-2}$ contour. The monsoon break is followed by a second convection enhancement from mid-August (pentads 45 and 46). During the monsoon break, the values of OLR along $150^{\circ} \mathrm{E}$ increase by about $20 \mathrm{~W} \mathrm{~m}^{-2}$ in comparison with previous and subsequent periods, which is about twice as large as that in the climatology, indicating a more remarkable monsoon break for the period 1979-2002.

There are no significant decadal differences in convection in late July (pentads 40-42) for the period 200311 (Fig. 3b). The convection becomes obviously enhanced in early August (pentads 43 and 44), when the monsoon break occurs for the period 1979-2002. The convection becomes suppressed in mid-August (pentads 45 and 46), indicating the occurrence of the monsoon break, when the convection is enhanced again for the period 19792002. This confirms the delay in the convection enhancement and subsequent monsoon break for the latter period. On the other hand, it seems that the evolution of convection from late July to mid-August tends to be out of phase in comparison with the former period.

The convection evolution is more clearly illustrated by Fig. 4, which shows the OLR averaged over the key region $\left(10^{\circ}-20^{\circ} \mathrm{N}, 140^{\circ}-160^{\circ} \mathrm{E}\right)$ for the periods 1979 2002 and 2003-11. The dominant feature is that the convection evolution is almost out of phase between the two periods from late July to mid-August. Specifically, for the period 1979-2002, the convection begins to intensify from mid-July (pentad 40) and reaches its peak in late July (pentad 42), with the OLR value decreasing from $235 \mathrm{~W} \mathrm{~m}^{-2}$ to below $215 \mathrm{~W} \mathrm{~m}^{-2}$. Subsequently, the convection weakens and is noticeably suppressed in early August (pentad 44) as the monsoon break occurs. The OLR value increases by about $15 \mathrm{~W} \mathrm{~m}^{-2}$ in comparison with the previous convection peak, and maintains at more than $225 \mathrm{~W} \mathrm{~m}^{-2}$ during the monsoon break. The convection undergoes a second enhancement in mid-August (pentads 45 and 46).

In contrast, for the period 2003-11, the OLR value stays at about $225 \mathrm{~W} \mathrm{~m}^{-2}$ during mid-to-late July (pentads 39-41) and decreases to below $210 \mathrm{~W} \mathrm{~m}^{-2}$ at the end of July (pentad 43) when the enhanced convection 


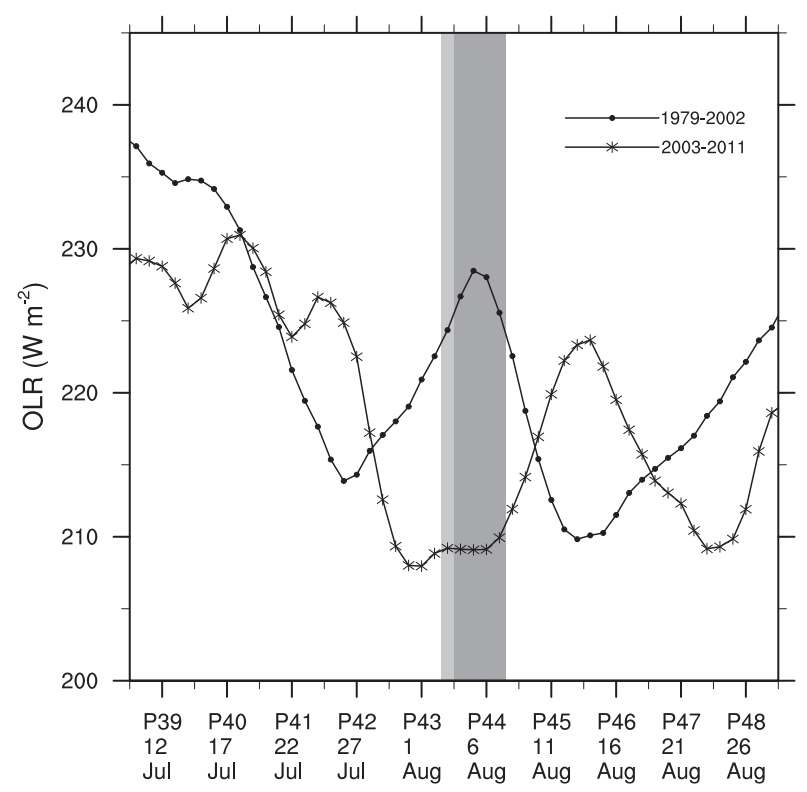

FIG. 4. Time series of the 5-day running mean OLR averaged over the key region $10^{\circ}-20^{\circ} \mathrm{N}, 140^{\circ}-160^{\circ} \mathrm{E}$ for the periods 1979 2002 and 2003-11. Light and dark shading indicate that the differences between the two periods are significant at the $90 \%$ and $95 \%$ confidence level, respectively, based on the Student's $t$ test. The labels on the abscissa locate the middle dates of each pentad.

reaches its peak. The strong convection is maintained through early August (pentads 44), when the monsoon break takes place for the period 1979-2002, and the differences in daily convection between the two periods are statistically significant during the climatological monsoon break period. Subsequently, associated with the delayed occurrence of the convection peak, the monsoon break occurs in mid-August (pentads 45 and 46), when the convection is enhanced again for the period 1979-2002. The connection between the previous convection peak and the subsequent monsoon break can be explained by the 10-25-day oscillations (Xu and $\mathrm{Lu}$ 2015), which usually tend to be in their wet phase when convection reaches its peak, and then transfer to their dry phase and thus contribute to the following monsoon break.

The above decadal phase change of the WNPSM is confirmed by the results of the $k$-means cluster analysis (Fig. 5). The subseasonal evolution of convection over the key region is classified into two clusters based on similarity. After several iterations of the $k$-means cluster algorithm, the center of cluster 1 still shows a similar feature to the mean evolution for the period 1979-2002, with the convection is reaching its peak in late July and the monsoon break appears in early August; whereas, the center of cluster 2 is almost out of phase and features delayed occurrences of the convection peak and

\section{(a) cluster centers}

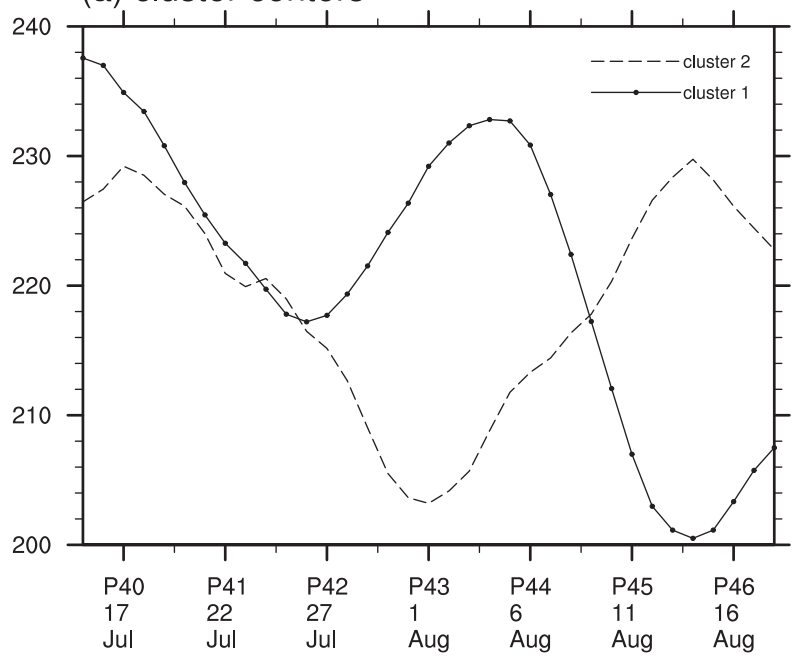

(b) cluster assigned

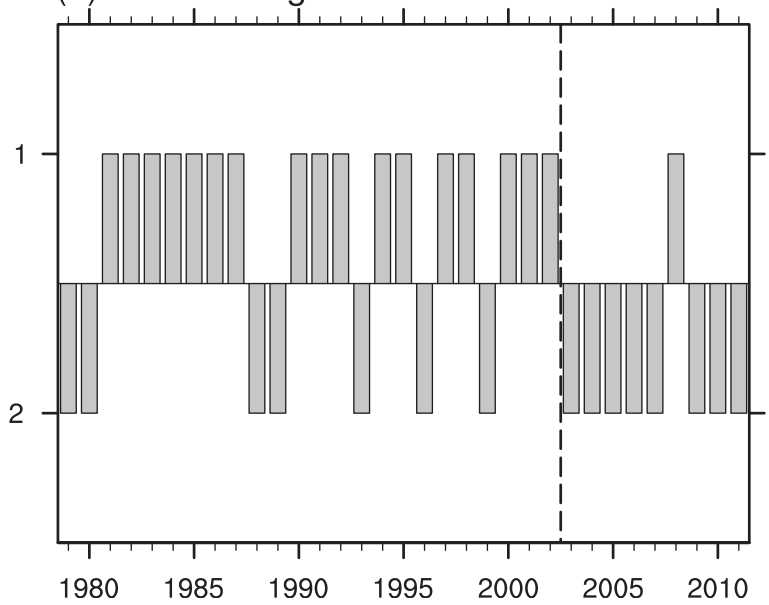

FIG. 5. (a) Two cluster centers derived by performing the $k$-means cluster analysis on the subseasonal evolution of convection (OLR) averaged over the key region $\left(\mathrm{W} \mathrm{m}^{-2}\right)$. (b) Cluster assigned for each year during 1979-2011.

monsoon break, which is similar to the mean evolution for the period 2003-11 (Fig. 4). We find that the subseasonal evolution of convection in more than two-thirds (17 out of 24) of years before 2002 belong to cluster 1 . In contrast, the subseasonal evolution during only one year after 2003 belongs to cluster 1, and all the remaining eight years belong to cluster 2 (Fig. 5b). This change in occurrence frequency for the two clusters confirms the decadal phase change of the WNPSM.

Figure 6 shows the spatial distribution of the $850-\mathrm{hPa}$ wind and geopotential height during pentads 41-46 for the periods 1979-2002 and 2003-11. For the former period (Figs. 6a-f), at pentad 41, the western extent of the subtropical high covers the WNP, with its ridge 

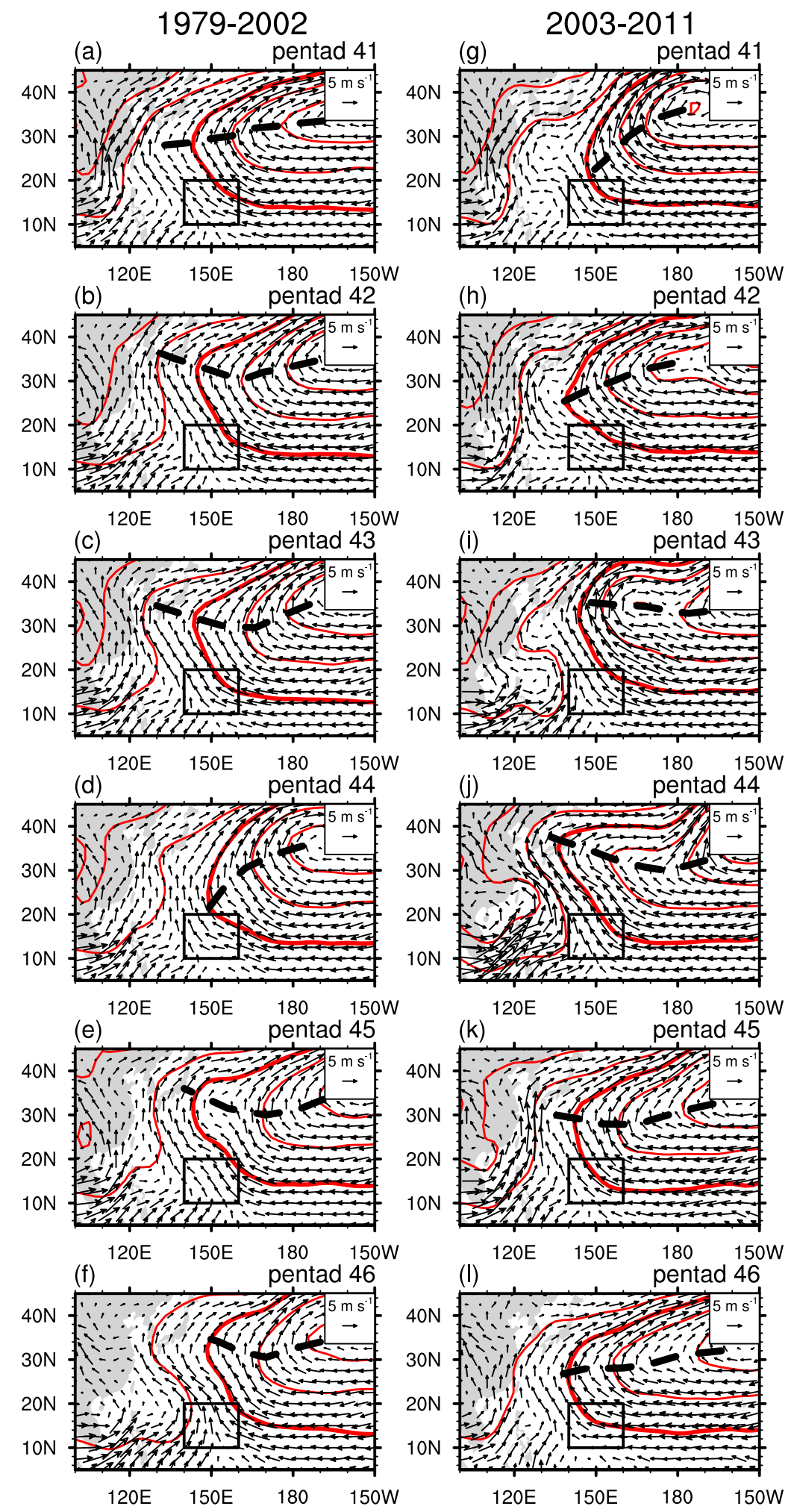

FIG. 6. Spatial distributions of $850-\mathrm{hPa}$ wind ( $\mathrm{m} \mathrm{s}^{-1}$; vectors) and geopotential height (gpm; contours) during pentads 41-46 for the periods (a)-(f) 1979-2002 and (g)-(l) 2003-11. The contour interval is $30 \mathrm{gpm}$, and the thick lines denote the contours of $1520 \mathrm{gpm}$. The dashed black lines indicate the ridges of the WNP subtropical high. Boxes mark the key region. 
(a) $1979-2002$

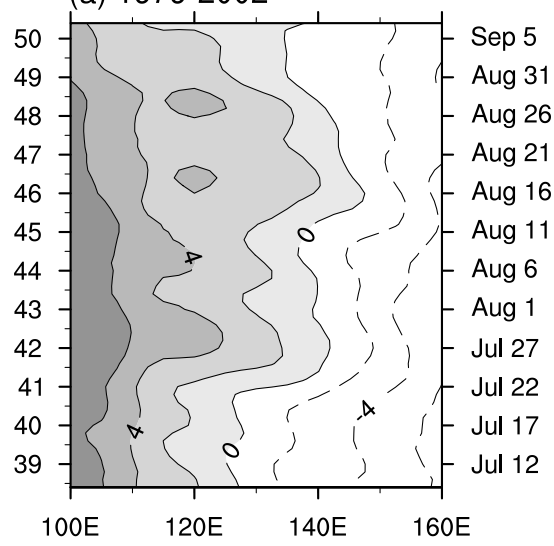

(b) $2003-2011$

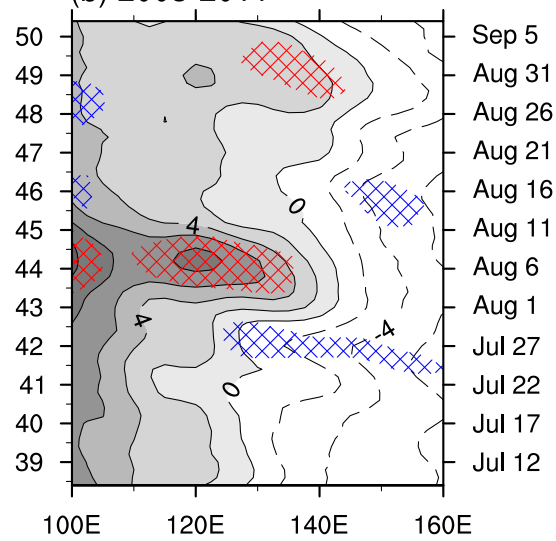

FIG. 7. Longitude-time cross section of the 5-day running mean zonal wind at $850 \mathrm{hPa}$ averaged between $10^{\circ}$ and $20^{\circ} \mathrm{N}$ for the periods (a) 1979-2002 and (b) 2003-11. The contour interval is $2 \mathrm{~m} \mathrm{~s}^{-1}$, and shading denotes values greater than $0 \mathrm{~m} \mathrm{~s}^{-1}$. The red (blue) marked areas in (b) denote that the positive (negative) differences between 2003-11 and 1979-2002 reach the $90 \%$ confidence level based on the Student's $t$ test.

stretching westward along approximately $30^{\circ} \mathrm{N}$. At the same time, the monsoon trough is located over the SCS. At pentad 42, the subtropical ridge displays a notably northward lift to the south of Japan. Concurrently, the monsoon trough moves eastward across the Philippines along with a strengthening of the monsoon westerlies. The confluence of the moist monsoon westerlies and the tropical easterlies favors the drastic development of deep convection over the WNP (Fig. 2). When the monsoon break appears at pentad 44, the subtropical ridge retreats significantly southward and is located in the north of the key region. Concurrently, the monsoon trough is weakened, and the convection over the key region becomes noticeably suppressed (Fig. 2). Subsequent to the monsoon break, the subtropical ridge shifts northward and the monsoon trough strengthens at pentads 45 and 46 , when the convection becomes enhanced again over the key region.

In contrast, for the period 2003-11 (Figs. 6g-1), at pentad 41, the subtropical ridge stretches southwestward to the north of the key region, and then moves slightly northward at pentad 42 . The locations of the ridge are much farther south relative to their counterparts for the period 1979-2002. Concurrently, the monsoon trough stays over the SCS during pentads 41 and 42 . Therefore, convection develops slowly over the WNP (Fig. 2). At pentad 43, the subtropical ridge suddenly jumps northward, and the monsoon trough penetrates the western Philippine Sea, which contributes to the flare-up of deep convection over the WNP (Fig. 2). The subtropical ridge continues moving northwestward at pentad 44 , when the monsoon trough is further intensified reflected by a noticeable intensification of southwesterlies. As a result, the strong convection is still maintained over the WNP (Fig. 2). The subtropical ridge gradually retreats southward at pentads 45 and 46 , concurrent with the weakening of the monsoon trough, when the monsoon break occurs over the key region.

Figure 7 shows a longitude-time cross section of the $850-\mathrm{hPa}$ zonal wind averaged between $10^{\circ}$ and $20^{\circ} \mathrm{N}$ for the periods 1979-2002 and 2003-11. Averages over these latitudes can accurately reflect the zonal shift of the monsoon trough over the WNP in boreal summer. The zero contours represent the location where the monsoon westerlies converge with the tropical easterlies (i.e., the location of the monsoon trough). For the period 19792002 (Fig. 7a), monsoon westerlies progress eastward strongly to $140^{\circ} \mathrm{E}$ in late July (pentads 41 and 42 ), indicating a quick establishment of the monsoon trough over the western Philippine Sea in concert with the rapid convection enhancement (Fig. 3a). Subsequently, the monsoon westerlies display slight disturbances and tend to weaken in early September, when the WNPSM starts to withdraw and convection becomes suppressed (Fig. 3a).

However, for the period 2003-11 (Fig. 7b), the monsoon westerlies are significantly weaker than those for the period 1979-2002 at pentad 42. The anomalous easterlies correspond to the southward-stretched subtropical ridge in the latter period, which had shifted northward in the former period (Figs. 6b,h). A sudden eastward march, accompanied by a noticeable enhancement of the monsoon westerlies, is observed until early August (pentads 43 and 44), which lags by about 10 days in comparison with the former period, corresponding to the delayed development of convection (Fig. 3b). 
Subsequently, the zonal variation in the monsoon trough is more remarkable and tightly connected to the evolution of convection for the latter period. The westerlies tend to weaken in mid-August (pentad 46) and strengthen again in late August (pentads 48 and 49), which corresponds to the monsoon break and the second convection enhancement, respectively (Fig. 3b).

In summary, the above results indicate that the phase evolution of the WNPSM, characterized by a previous convection enhancement and a subsequent monsoon break, tends to be delayed for the period 2003-11, and is thus out of phase with that of the period 1979-2002 (Figs. 2-4). In particular, for the latter period, the enhanced convection reaches its peak in early August, when the monsoon break occurs for the former period of 1979-2002. In addition, corresponding to the convection evolution, the circulations, mainly represented by the monsoon trough and the WNP subtropical high, also exhibit remarkably different evolutions between the two periods.

\section{Impact of SSTs on the decadal change in the monsoon break}

Figure 8 shows the SST difference between the periods 2003-11 and 1979-2002 over the tropical western Pacific during pentads 40 and 41 (15-24 July). The contours of $28.5^{\circ}$ and $29^{\circ} \mathrm{C}$ are shown to illustrate the general outline of the western Pacific warm pool in the climatology. The SST change is shown as a horseshoe-shaped warming pattern that extends from the eastern extent of the warm pool to the subtropical Pacific. In particular, two significant warming regions are located around the rim of the warm pool-one centered at about $20^{\circ} \mathrm{N}, 170^{\circ} \mathrm{E}$, with an amplitude of over $0.6^{\circ} \mathrm{C}$, and the other zonally elongated and extending from about $140^{\circ} \mathrm{E}$ to $150^{\circ} \mathrm{W}$ along $5^{\circ}-20^{\circ} \mathrm{S}$, with its highest value being greater than $0.8^{\circ} \mathrm{C}$. This SST change suggests eastward and southward expansions of the warm pool in the northwestern and southwestern Pacific, respectively, in the latter period. In fact, the SST warming over the tropical western Pacific is not unique to pentads 40 and 41 , and it appears in the preceding winter and lasts until the subsequent summer (figures not shown). The decadal warming of SST in this region has also been noted by Ha and Zhong (2015), who suggested that the SST warming plays an important role in the decadal change of tropical cyclone (TC) activity. However, the mechanism for this SST change is still unknown.

Generally, warmer SSTs over the WNP are expected to provide more favorable thermodynamic conditions for convection development, thus favoring an advanced

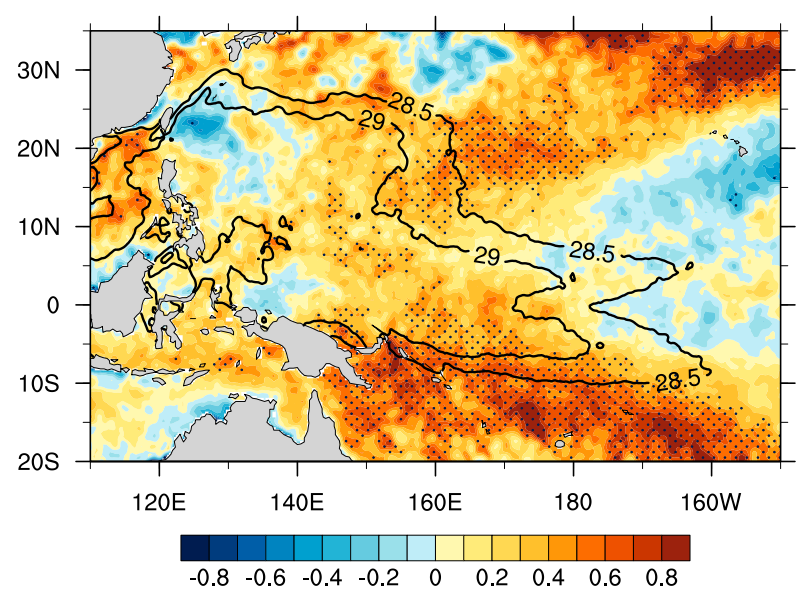

FIG. 8. Differences in SST $\left({ }^{\circ} \mathrm{C}\right.$; color shading) between the periods 2003-11 and 1979-2002 during pentads 40 and 41. Values exceeding the $95 \%$ confidence level, based on the Student's $t$ test, are stippled. The contours of $28.5^{\circ}$ and $29^{\circ} \mathrm{C}$ indicate the climatological mean SST.

establishment of strong convection. However, as the results shown in section 3 indicate, the occurrence of drastic convection enhancement over the WNP for the latter period lags behind that of the former period by about 1-2 pentads. This implies that the convection over the key region may be influenced not only by the local SST in the WNP, but also by SSTs in remote regions.

Figure 9 shows the SST evolution in the western $\mathrm{Pa}$ cific warm pool region from mid-July to early August for the periods 1979-2002 and 2003-11. For the former period (Figs. 9a-d), during pentads 40 and 41 , the SST in the northern extent of the warm pool is warmer than that in the southern extent, which provides more favorable thermodynamic conditions for convection development and promotes the northward shift of the strong convection band, leading to drastic convection enhancement over the key region at pentad 42 (Fig. 2b). This indicates an SST-forcing-the-atmosphere process. The SST-convection relationship is consistent with that reported by Lau et al. (1997), who suggested that in the warm pool region, owing to the large-scale strong uppertropospheric divergence, warmer SSTs favor convection development unless SSTs are as high as $30^{\circ} \mathrm{C}$. Afterward, an atmosphere-forcing-the-SST process appears: in response to the noticeably enhanced convection, the SST in the northern extent tends to decrease continuously at pentads 42 and 43 . The persistent SST cooling in turn hinders the development of convection, and finally the monsoon break occurs at pentad 44, when the SST is found to increase in coincidence with the significant convection suppression (Fig. 2d). The above 
1979-2002

(a)

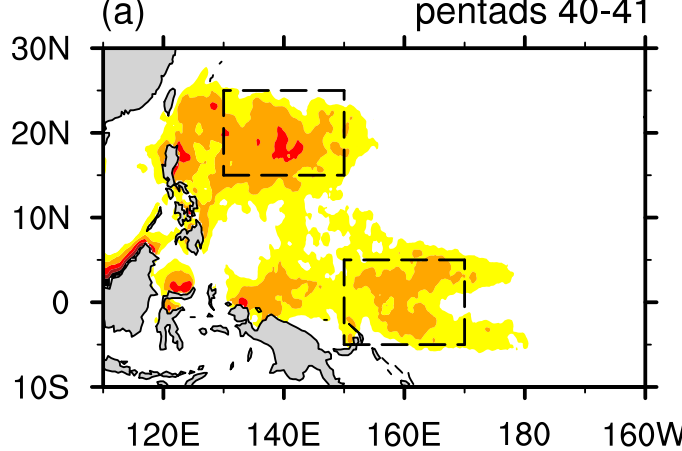

(b)

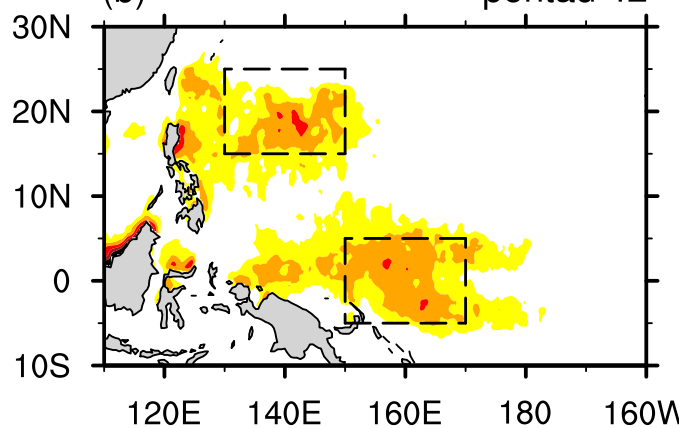

(c)

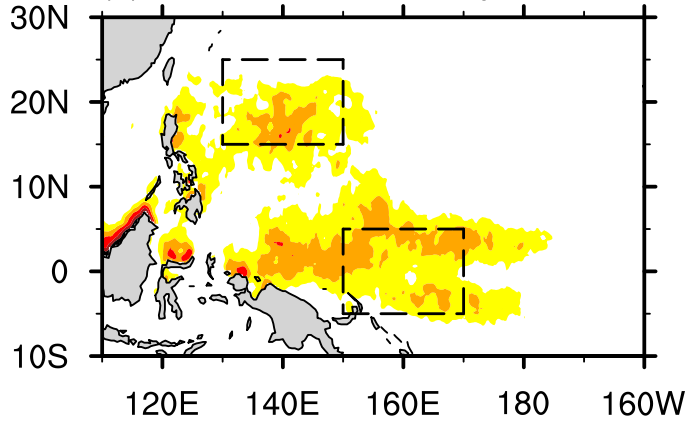

(d)

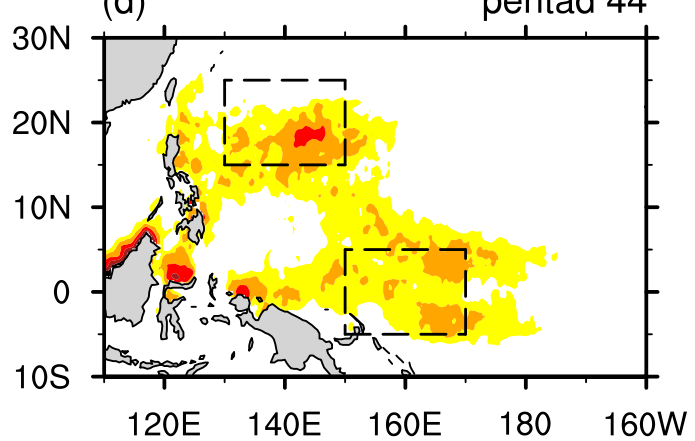

(e) 2003-2011 pentads $40-41$
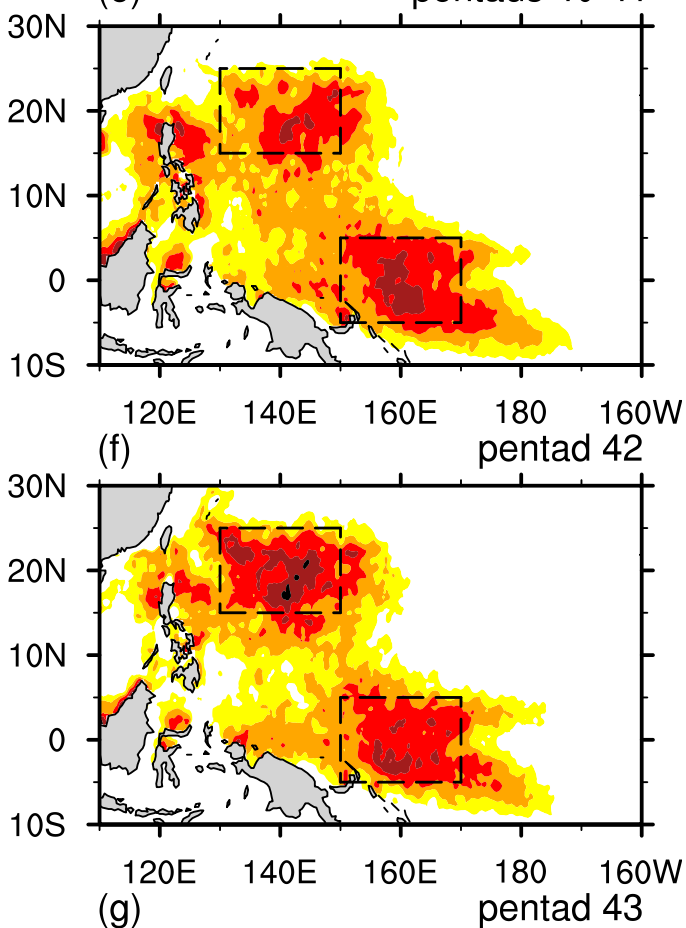

(g)

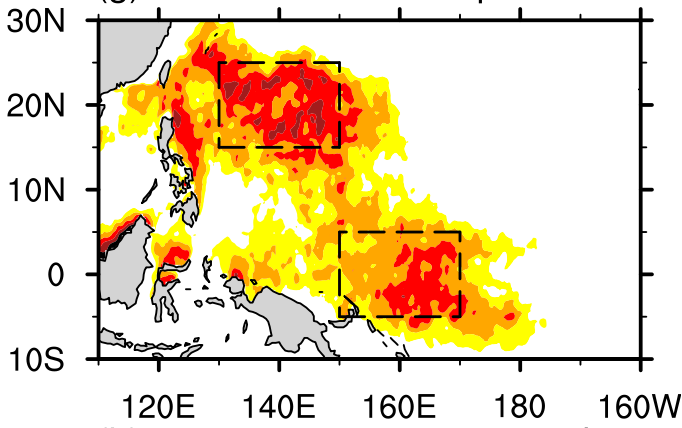

(h)

$10 \mathrm{~S}$

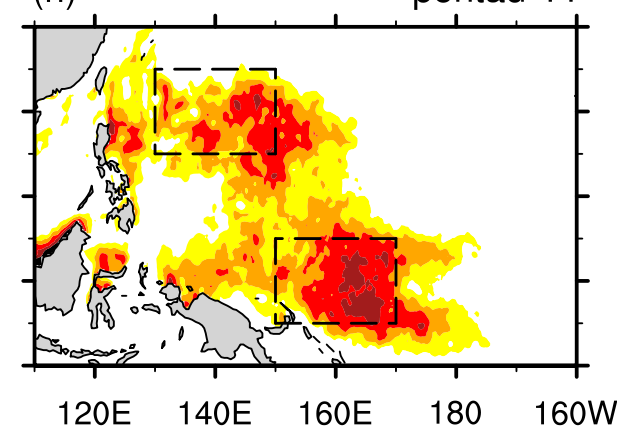

29.8

FIG. 9. Spatial distributions of SST at pentads 40-41, 42, 43, and 44 for the periods (a)-(d) 1979-2002 and

(e)-(h) 2003-11. The dashed boxes mark the regions defined for the north and south SST centers. 
subseasonal variations of SST and convection indicate a close interaction between them.

In contrast, for the period 2003-11 (Figs. 9e-h), the SST in the warm pool at pentads 40 and 41 is warmer in comparison with the former period, particularly in the southern extent, where the SST is even higher than that in the northern extent. This meridional SST contrast is opposite to that found in 1979-2002. Accordingly, the convection is found to be remarkably enhanced in the southern extent of the warm pool at pentad 42 (Fig. 2h), when the local SST decreases as a response to the strong convection. On the contrary, the SST in the northern extent increases noticeably at pentad 42 under the relatively weak convection there (Fig. 2h) and becomes higher than in the southern extent. This reversed meridional SST contrast finally contributes to the rapid enhancement of convection over the key region at pentads 43 and 44 (Figs. $2 \mathrm{i}$ and 2j, respectively), when the SST in the northern extent decreases correspondingly.

To quantitatively estimate the subseasonal evolution of SST over the tropical western Pacific, the north SST center is defined as $15^{\circ}-25^{\circ} \mathrm{N}, 130^{\circ}-150^{\circ} \mathrm{E}$, and the south SST center as $5^{\circ} \mathrm{S}-5^{\circ} \mathrm{N}, 150^{\circ}-170^{\circ} \mathrm{E}$. The regions are defined based on the average locations of the two warmest SST centers from mid-July to early August (Fig. 9). It should be mentioned that the northern area is slightly different from the key region for convection, which may be due to the modulating role of large-scale atmospheric circulation (Lau et al. 1997). Figure 10 shows the time series of SST in these two centers (red lines in Fig. 10a and blue lines in Fig. 10b) and OLR averaged over the key region and the equatorial western Pacific (black lines). For the period 1979-2002 (Fig. 10a), the SST in the north center (red solid line) maintains at about $29.2^{\circ} \mathrm{C}$ during pentads 40 and 41 , which is higher than in the south center (red dashed line), thus favoring the convection development over the key region (black solid line). Subsequently, and concurrently with the complete enhancement of convection at pentad 42 , the SST in the north center begins to decrease and leads to the weakening of convection over the key region. Finally, the monsoon break occurs at pentad 44 when the SST increases slightly. In contrast, the amplitude of SST variation in the south center is relatively small. However, it should be noted that the evolution of convection always seems to lag that of SST.

For the 2003-11 period (Fig. 10b), the SST in the south center (blue dashed line) at pentads 40 and 41 increases by more than $0.3^{\circ} \mathrm{C}$ in comparison with the former period (1979-2002; red dashed line in Fig. 10a) and is higher than the north center (blue solid line). This meridional SST contrast may contribute to stronger

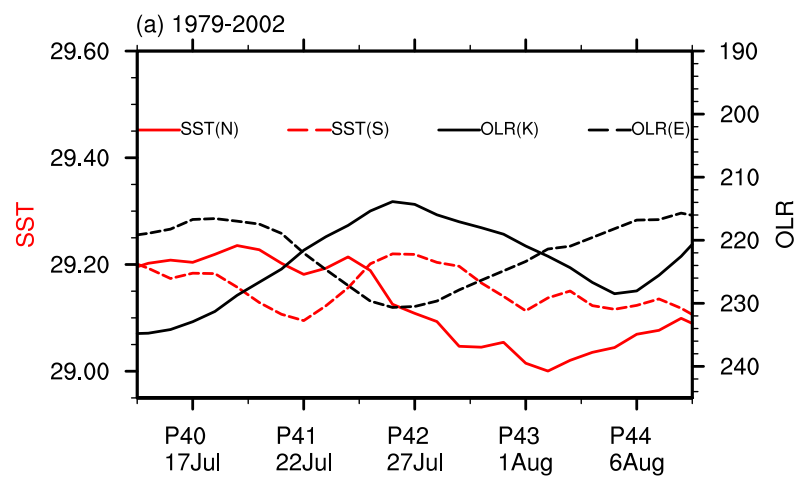

(b) 2003-2011

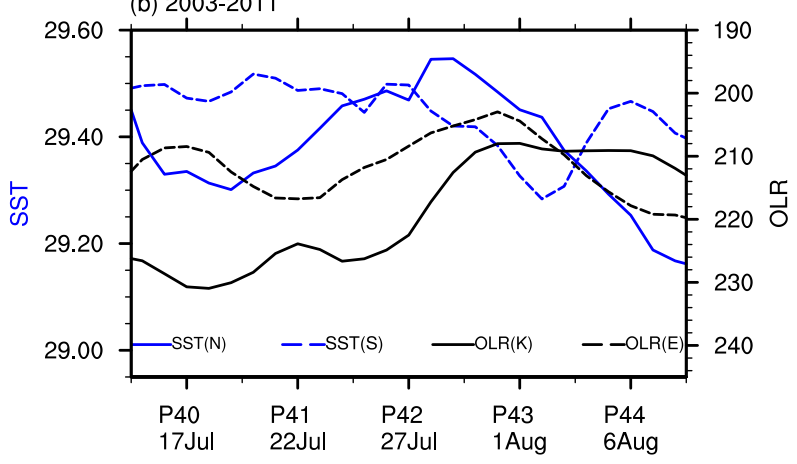

(c) North minus south

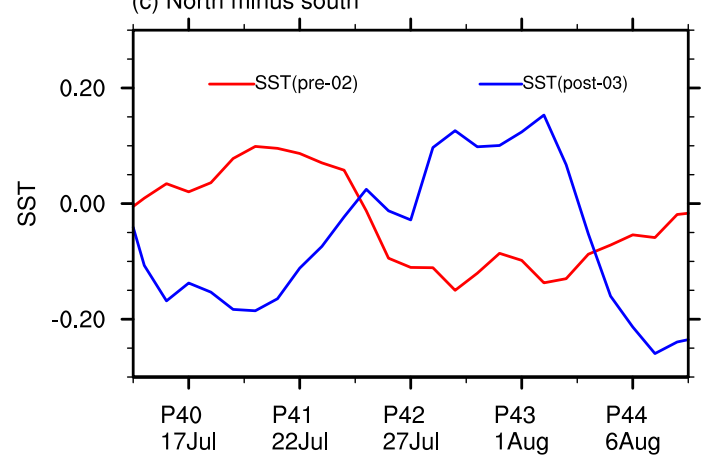

FIG. 10. Time series of SST $\left({ }^{\circ} \mathrm{C}\right)$ for the periods (a) 1979-2002 and (b) 2003-11 in the north (solid) and south (dashed) centers [red lines in (a) and blue lines in (b)] and OLR ( $\mathrm{W} \mathrm{m}^{-2}$; black lines) averaged over the key region (solid) and the equatorial western Pacific (dashed). (c) Difference in SST $\left({ }^{\circ} \mathrm{C}\right)$ between the north and south centers for the periods 1979-2002 (red) and 2003-11 (blue). The labels on the abscissa locate the middle dates of each pentad. The values of the right ordinate are reversed with values increasing from top to bottom in (a) and (b).

convection over the equatorial western Pacific, which continues enhancing at pentad 42 (black dashed line), when the SST in the south center decreases as a response. In contrast, the SST in the north center increases in pentad 41 because of the relatively weak convection there, and becomes higher than the south center at pentad 42. This reversed meridional SST contrast promotes the rapid development of convection over the key 
region (black solid line), which reaches its peak at pentads 43 and 44 when the SST in the north center decreases quickly.

The lead-lag relationship between the evolution of SST in the north (south) center and OLR over the key region (equatorial western Pacific) during mid-Julyearly August (Figs. 11a,b) is further examined. Specifically, the time series of SST are fixed at pentads 40-44 (days 196-220), and OLR series shift backward or forward according to the lead or lag days of SST. For instance, the value at day -10 refers to the correlation coefficient between SST (days 196-220) and OLR (days 206-230), and thus SST leads OLR. Similarly, the value at day 10 refers to the correlation coefficient between SST (days 196-220) and OLR (days 186-210), and thus SST lags OLR. The lead-lag correlation coefficients are calculated in each year, and then averaged over 19822012. It shows that negative correlation occurs when SST in the north (south) center leads OLR over the key region (equatorial western Pacific), with a maximum at -6 or -7 days, indicating SST warming (cooling) will favor the subsequent convection enhancement (suppression). This implies a process of the ocean influencing the atmosphere, which is implemented through SST gradually modifying the surface air temperature, humidity, and atmospheric instability (e.g., Wu 2010; Ye and $\mathrm{Wu}$ 2015). This gradual process leads to a time lag of convection behind SST of about 1-2 pentads (Arakawa and Kitoh 2004; Wu et al. 2008). On the other hand, positive correlation occurs when SST in the north (south) center lags OLR over the key region (equatorial western Pacific), indicating that the enhanced (depressed) convection will lead to a subsequent SST decrease (increase), which reflects a process of the atmosphere influencing the ocean. This SST-convection relationship is consistent with the results in Fig. 10 and confirms strong air-sea interactions on the subseasonal time scale in the warm pool region. The simultaneous correlation over the northern region is near zero but is clearly positive over the southern region, implying that once the convection becomes enhanced over the southern region, the SST decreases more quickly in response. The symmetry displayed in the SST-convection relationship over the northern region may be associated with the local active intraseasonal oscillations, which in contrast are inactive over the southern region (e.g., Hsu and Weng 2001; Fukutomi and Yasunari 2002; Chen and Sui 2010).

It is noted that the contrast in meridional SSTs tends to be opposite between the former and latter period from late July to early August, which can be seen more clearly from the evolution of the difference in SST between the north and south centers, as shown in Fig. 10c. The decadal change in the SST meridional contrast is
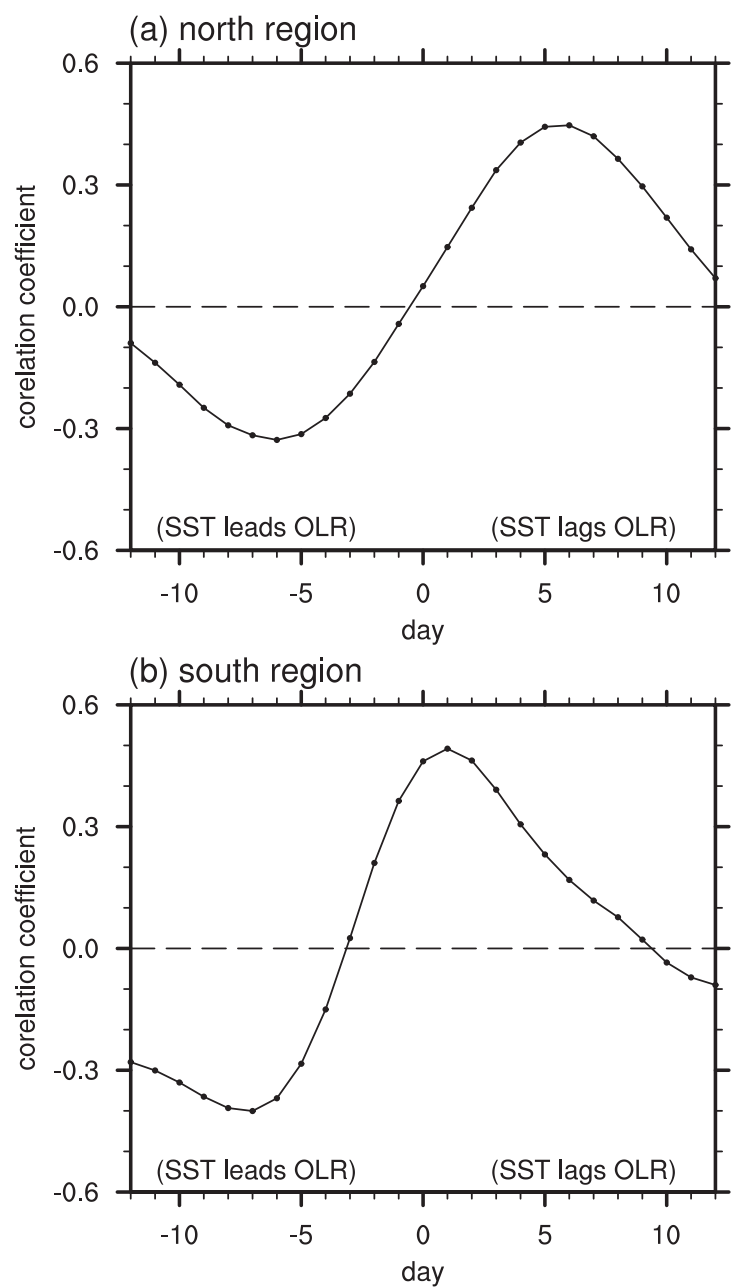

(c) north minus south

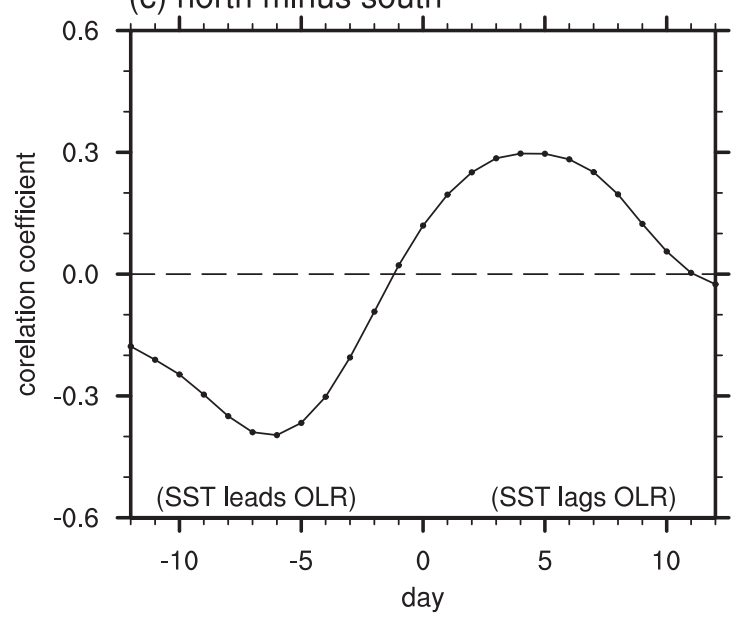

FIG. 11. Lead-lag correlation coefficients between the (a) SST over the north center and OLR over the key region, (b) SST over the south center and OLR over the equatorial western Pacific, and (c) SST meridional difference (north minus south region) and OLR meridional difference (key region minus equatorial western $\mathrm{Pa}$ cific). See section 4 for details. Negative (positive) days denote SSTs leading (lagging) OLR. 
statistically significant at the $98 \%$ confidence level, according to the Student's $t$ test. This is determined by calculating the difference in the SST meridional contrast between pentads $40-41$ and pentads $42-43$ in each year due to the sign transition between pentads 41 and 42 for both periods (Fig. 10c), and then the 30 derived values are tested between 1982-2002 and 2003-11. This indicates that the decadal change in the evolution of convection over the WNP is closely associated with the meridional SST contrast over the tropical western $\mathrm{Pa}$ cific. Figure 11c shows the lead-lag correlation between the SST meridional difference (north center minus south center) and the OLR meridional difference (key region minus the equatorial western Pacific). Negative correlation appears when the SST difference leads the OLR difference, which indicates that warmer SSTs in the north (south) region will lead to subsequently stronger convection over the key region (equatorial western $\mathrm{Pa}$ cific) through the provision of more favorable conditions for convection development. On the other hand, the positive correlation when the SST difference lags the OLR difference indicates that stronger convection over the key region (equatorial western Pacific) will, in turn, contribute to locally cooler SSTs over the north (south) region. This is consistent with the results shown in Figs. 9 and 10. In particular, for the period 2003-11, the much warmer SST in the south center at pentads 40 and 41 favors convection enhancement nearby at pentad 42 , when the convection over the key region remains relatively weak (Fig. 2). Therefore, it is speculated that enhanced convection in the southern extent of the warm pool may inhibit the development of convection over the key region through a local meridional circulation, thus leading to a delayed occurrence of the convection peak over the key region.

Figure 12 shows latitude-height cross sections of wind difference between the periods 2003-11 and 1979-2002 averaged along $140^{\circ}-160^{\circ} \mathrm{E}$, where the key region is located. The latitudinal distributions of decadal differences in low-level integrated moisture flux divergence are also shown. At pentads 40 and 41, significant upward motion appears in the lower and middle troposphere south of the equator where the low-level moisture flux converges, associated with the remarkable warming of SSTs in the southern extent of the warm pool for the latter period (Fig. 9). At the same time, anomalous downward motion is observed over $10^{\circ}-15^{\circ} \mathrm{N}$, where the divergence of moisture flux is located, and anomalous southerly and northerly winds appear in the upper and lower troposphere, respectively. These meridional and vertical winds constitute a local meridional circulation. At pentad 42, as the moisture flux convergence and divergence become stronger, this meridional circulation intensifies, with the vertical motion being significantly enhanced and expanded to the whole troposphere, and moves northward slightly. Therefore, for the latter period, even though the local SST in the northern extent is warmer in comparison with the former period (Fig. 9), the development of convection over the key region is inhibited at pentads $40-42$ because of the unfavorable downward motion. On the other hand, the SST in the northern extent increases under this persistent anomalous downward motion, and becomes higher than the southern extent at pentad 42 (Fig. 9). Associated with the reversal of the meridional SST contrast, the convergence of moisture flux and anomalous upward motion appear and intensify over the key region at pentads 43 and 44 , leading to the collapse of the local meridional circulation. Therefore, under these favorable conditions, including both the upward motion and warmer SST in the northern extent, the convection over the key region becomes drastically enhanced for the latter period. The maximum intensity of the convection is stronger than that in the former period (Fig. 4), which may be attributable to the warmer SST in the WNP for the latter period.

The above results confirm the hypothesis that for the latter period (2003-11), the anomalous warming of SST in the southern extent of the warm pool during mid- and late July induces significant convection enhancement nearby, which inhibits the development of convection over the key region through a local meridional circulation, and thus contributes to the delay of the convection peak. This role played by SSTs on the decadal time scale is different from that in the climatology proposed by $\mathrm{Wu}$ (2002), who highlighted the importance of zonal SST gradients to the development of convection associated with the WNPSM onset. This difference may be attributable to the different time scales [i.e., decadal change in the present study and climatological evolution in $\mathrm{Wu}$ (2002)].

In addition to SSTs, intraseasonal oscillations have also been found to modulate the WNPSM's evolution. For instance, Wu and Wang (2000) suggested that intraseasonal oscillations play an important role in regulating the interannual variability of monsoon onset. $\mathrm{Wu}$ and Wang (2001) highlighted a joint contribution of intraseasonal oscillations and the seasonal cycle to the multistage monsoon onset in the climatology. $\mathrm{Xu}$ and $\mathrm{Lu}$ (2015) found that strengthened 10-25-day oscillations in late summer are crucial in forming the WNPSM break. Therefore, the behavior of intraseasonal oscillations for the periods 1979-2002 and 2003-11 are examined, revealing that they exhibit a delayed phase around both the periods of the convection peak and the monsoon break between these two periods (figures not shown), 
(a) pentads $40-41$

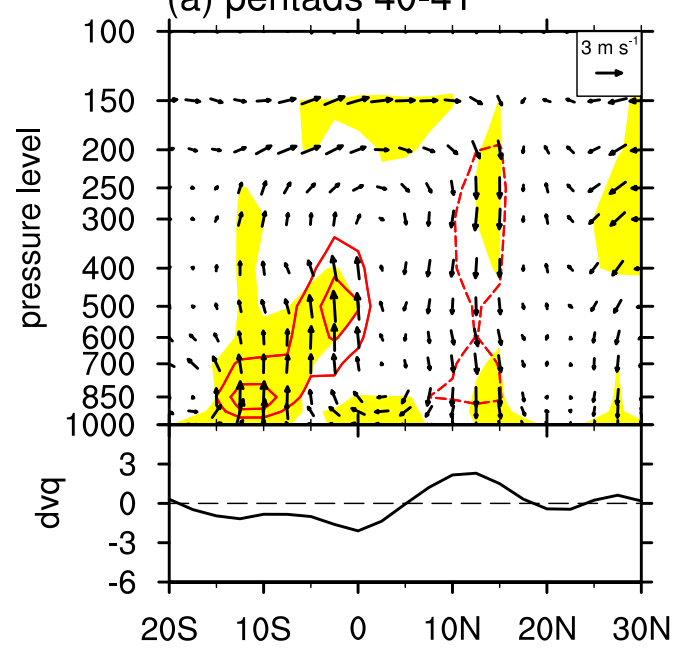

(b) pentad 42

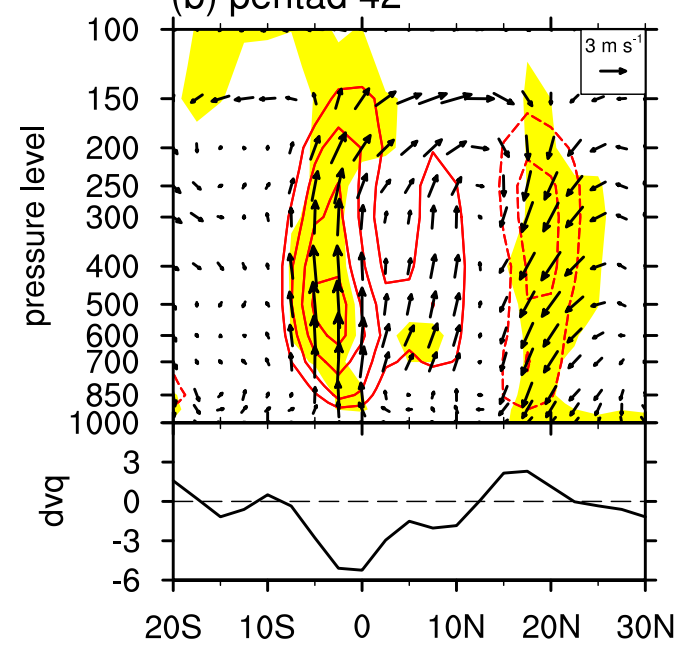

(c) pentad 43

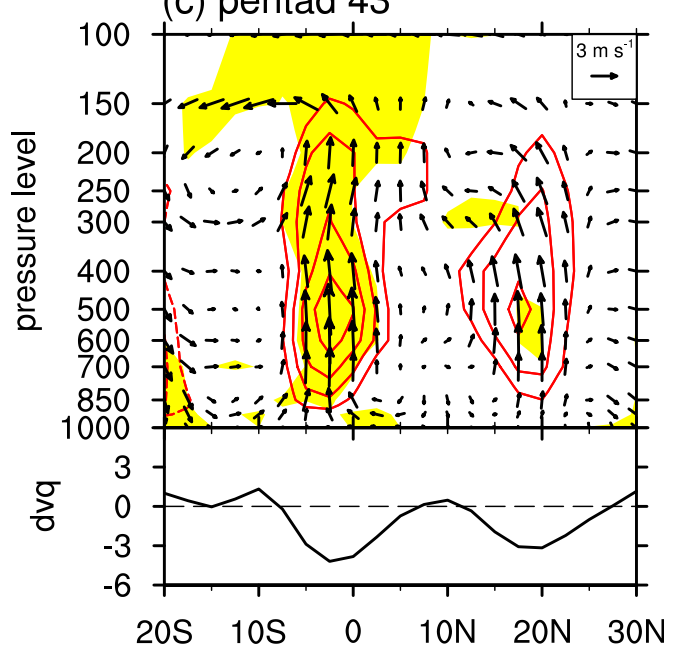

(d) pentad 44

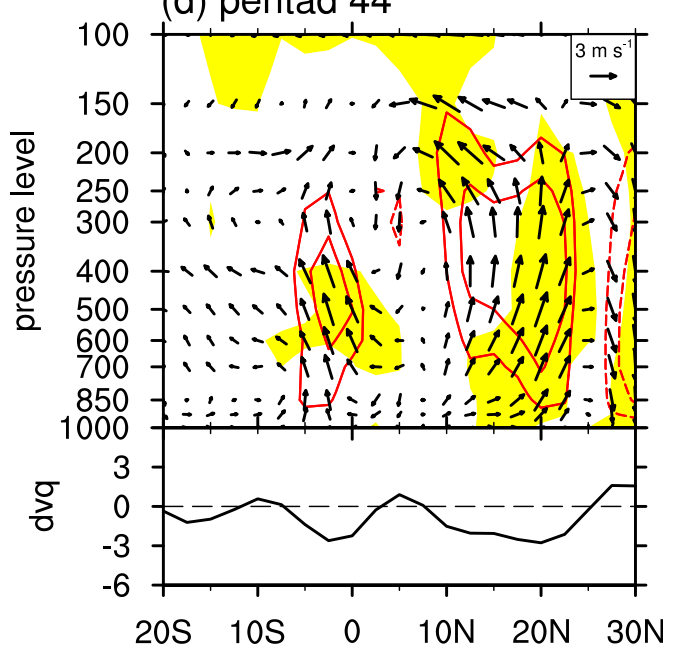

FIG. 12. Latitude-vertical cross sections of differences (2003-11 minus 1979-2002) of wind vectors (with vertical pressure velocity multiplied by -100 ) averaged along $140^{\circ}-160^{\circ} \mathrm{E}$ at pentads (a) $40-41$, (b) 42 , (c) 43 , and (d) 44 . The scale for the vectors is shown in the upper-right corner. Yellow shading indicates that either the meridional or vertical component of the wind reaches the 95\% confidence level, based on the Student's $t$ test. Contours indicate the values of vertical pressure velocity, with the interval being $1 \times 10^{-2} \mathrm{~Pa} \mathrm{~s}^{-1}$, and the zero contours are omitted. The latitudinal distributions of decadal differences of moisture flux divergence $\left(10^{-7} \mathrm{~kg} \mathrm{~m}^{-2} \mathrm{~s}^{-1}\right)$, which is integrated vertically from 1000 to $700 \mathrm{hPa}$, are also shown at the bottom of (a)-(d).

implying their contribution to the delayed WNPSM evolution in the latter period. But is this phase shift of intraseasonal oscillations between the two periods related to the decadal change in the seasonal evolution present in this study? And if so, how does the seasonal evolution modulate the shift in intraseasonal oscillations? These questions need further exploration.

\section{Conclusions and discussion}

In this study, a significant decadal change is detected in the phenomenon of the WNPSM break around the early 2000s. According to the moving Student's $t$ test, the abrupt point of this decadal change is in 2002/03. The subseasonal evolution related to the monsoon break shows remarkable differences between the periods 1979-2002 and 2003-11.

For the former period, the monsoon break occurs in early August, accompanied by significant convection suppression over the WNP; or, more exactly, over the region to the east of the Mariana Islands. It is sandwiched between two convection enhancements, one in late July and the other in mid-August. This evolution of convection is consistent with the climatological mean 
results shown by $\mathrm{Xu}$ and $\mathrm{Lu}$ (2015). In contrast, for the latter period, the monsoon break is delayed until midAugust, and the convection shows an out-of-phase evolution in comparison with the former period. This can be attributed to the differences in the evolution of the WNPSM. For the latter period, the convection continues strengthening in late July and reaches its peak in early August, when the monsoon break takes place for the former period, and thus the difference in convection between the two periods is quite significant. This delayed occurrence of the convection peak contributes to the delay in the following monsoon break. Corresponding to these differences in convection, the evolution of circulations, mainly represented by the monsoon trough and the WNP subtropical high, also exhibit remarkable differences between the two periods.

As the tropical convection is closely related to the SST, the differences in SST between the periods 2003-11 and 1979-2002 are examined. It is found that the western Pacific warm pool for the latter period is much warmer and expanded in comparison with the former period. Generally, locally warmer SSTs are expected to provide more favorable conditions for convection development, and thus favor an advanced establishment of strong convection. This indicates that the delayed occurrence of the convection peak over the WNP for the latter period may be influenced by SSTs in other remote regions. The SST evolutions in the entire warm pool region from mid-July to early August are also investigated, revealing that the different SST evolutions, which are particularly reflected by the meridional SST contrast, between the two periods, are responsible for the decadal change in the WNPSM's evolution related to the monsoon break. For the period 19792002, the SST in the northern extent of the warm pool is warmer than in the southern extent in mid- and late July. The conditions are more beneficial to the development of convection in the northern extent, and thus contribute to the northward shift of the strong convection band and complete enhancement of convection to the east of the Mariana Islands in late July. In contrast, for the period 2003-11, the SST in the southern extent of the warm pool is notably warmer, and tends to be higher than in the northern extent in mid- and late July. This reversed meridional SST contrast in comparison with the former period contributes to noticeable convection enhancement in the southern extent of the warm pool, which inhibits the development of convection to the east of the Mariana Islands through a local meridional circulation. As the SST in the northern extent continues warming and becomes higher than that in the southern extent, the convection to the east of the Mariana Islands is intensified until early August. Correspondingly, the subsequent monsoon break is also delayed until mid-August.
Concurrent with the decadal change in the WNPSM break, the large-scale circulations over East Asia have also been reported to have undergone decadal changes around the early 2000s, such as a decrease in TCs over the SCS (Ha and Zhong 2015), and the variation in summer precipitation over eastern China (Xu et al. 2015; Zhu et al. 2015). Whether the above decadal changes are independent or induced by common large-scale background variations, such as the change in SST, needs to be further investigated. Furthermore, how the break of the WNPSM will behave in the future is also of great interest. Will it return to its original state, maintain its current state, or even generate new changes? This may, according to the present results, depend on the variation in SSTs in the future, but this is still far from certain and therefore requires further study.

The present study focuses on decadal change in SSTs in the western Pacific warm pool (i.e., decadal change in local or adjacent SSTs). However, it should be noted that decadal change in SSTs may have a broad spatial structure. In fact, besides the warming in the western Pacific shown in Fig. 8, SSTs also become warmer in the Indian Ocean but only change slightly in the central and eastern Pacific in the period 2003-11 (not shown). The enhanced zonal SST gradient associated with these SST changes, as well as an enhanced Walker circulation (e.g., Dong and $\mathrm{Lu}$ 2013; England et al. 2014), may affect the climate over the WNP. Besides the zonal gradient of SSTs in the tropics, previous research has implied that extratropical SSTs may also have the potential to modulate convective activity over the WNP (e.g., Wu et al. 2009; Wu and Lin 2012; Wu et al. 2012). Whether these remote SSTs play a role in this decadal change of the WNPSM evolution associated with the monsoon break should be further explored in future work.

Finally, the onset of the WNPSM, as well as the break, is closely related to the subseasonal evolution of the WNPSM. Therefore, it is reasonable to hypothesize that the decadal change in SSTs affects both the onset and break by modulating the subseasonal evolution of the WNPSM. The change in the onset is also investigated, through various approaches, but significant decadal change in the monsoon onset around 2002/03 is not found. However, this does not necessarily indicate no decadal change in the onset of the WNPSM, since the failure to find statistically significant change may be attributable to inadequate sampling and/or strong noise induced by synoptic-scale disturbances such as TCs. Therefore, whether the onset of the WNPSM also undergoes a decadal change, as the break does, remains an open question.

Acknowledgments. The authors greatly appreciate the comments from the three anonymous reviewers, which helped considerably in providing an accurate 
description of our results. This work was supported by the National Natural Science Foundation of China (Grant 41320104007).

\section{REFERENCES}

Annamalai, H., and J. M. Slingo, 2001: Active/break cycles: Diagnosis of the intraseasonal variability of the Asian summer monsoon. Climate Dyn., 18, 85-102, https://doi.org/10.1007/ s003820100161.

Arakawa, O., and A. Kitoh, 2004: Comparison of local precipitation-SST relationship between the observation and a reanalysis dataset. Geophys. Res. Lett., 31, L12206, https:// doi.org/10.1029/2004GL020283.

Chen, G., and C.-H. Sui, 2010: Characteristics and origin of quasibiweekly oscillation over the western North Pacific during boreal summer. J. Geophys. Res., 115, D14113, https://doi.org/ 10.1029/2009JD013389.

Christiansen, B., 2007: Atmospheric circulation regimes: Can cluster analysis provide the number? J. Climate, 20, 2229 2250, https://doi.org/10.1175/JCLI4107.1.

Dong, B., and R. Lu, 2013: Interdecadal enhancement of the Walker circulation over the tropical Pacific in the late 1990s. Adv. Atmos. Sci., 30, 247-262, https://doi.org/10.1007/ s00376-012-2069-9.

England, M. H., and Coauthors, 2014: Recent intensification of wind-driven circulation in the Pacific and the ongoing warming hiatus. Nat. Climate Change, 4, 222-227, https://doi.org/ 10.1038/nclimate2106.

Fukutomi, Y., and T. Yasunari, 2002: Tropical-extratropical interaction associated with the 10-25-day oscillation over the western Pacific during the northern summer. J. Meteor. Soc. Japan, 80, 311-331, https://doi.org/10.2151/jmsj.80.311.

Gadgil, S., and P. V. Joseph, 2003: On breaks of the Indian monsoon. J. Earth Syst. Sci., 112, 529-558, https://doi.org/10.1007/ BF02709778.

Goswami, B. N., and R. S. Ajaya Mohan, 2001: Intraseasonal oscillations and interannual variability of the Indian summer monsoon. J. Climate, 14, 1180-1198, https://doi.org/10.1175/ 1520-0442(2001)014<1180:IOAIVO > 2.0.CO;2.

Ha, Y., and Z. Zhong, 2015: Decadal change in tropical cyclone activity over the South China Sea around 2002/03. J. Climate, 28, 5935-5951, https://doi.org/10.1175/JCLI-D-14-00769.1.

Hsu, H.-H., and C.-H. Weng, 2001: Northwestward propagation of the intraseasonal oscillation in the western North Pacific during the boreal summer: Structure and mechanism. J. Climate, 14, 3834-3850, https://doi.org/10.1175/1520-0442 (2001) $014<3834$ :NPOTIO > 2.0.CO;2.

Johnson, N. C., and S. B. Feldstein, 2010: The continuum of North Pacific sea level pressure patterns: Intraseasonal, interannual, and interdecadal variability. J. Climate, 23, 851-867, https:// doi.org/10.1175/2009JCLI3099.1.

Kanamitsu, M., W. Ebisuzaki, J. Woollen, S.-K. Yang, J. J. Hnilo, M. Fiorino, and G. L. Potter, 2002: NCEP-DOE AMIP-II Reanalysis (R-2). Bull. Amer. Meteor. Soc., 83, 1631-1643, https://doi.org/10.1175/BAMS-83-11-1631.

Krishnan, R., C. Zhang, and M. Sugi, 2000: Dynamics of breaks in the Indian summer monsoon. J. Atmos. Sci., 57, 1354-1372, https:// doi.org/10.1175/1520-0469(2000)057<1354:DOBITI >2.0.CO;2.

Lau, K.-M., H.-T. Wu, and S. Bony, 1997: The role of large-scale atmospheric circulation in the relationship between tropical convection and sea surface temperature. J. Climate, 10,
381-392, https://doi.org/10.1175/1520-0442(1997)010<0381: TROLSA $>2.0 . \mathrm{CO} ; 2$.

Liebmann, B., and C. A. Smith, 1996: Description of a complete (interpolated) outgoing longwave radiation dataset. Bull. Amer. Meteor. Soc., 77, 1275-1277.

Lu, R., H. Ding, C.-S. Ryu, Z. Lin, and H. Dong, 2007: Midlatitude westward propagating disturbances preceding intraseasonal oscillations of convection over the subtropical western North Pacific during summer. Geophys. Res. Lett., 34, L21702, https:// doi.org/10.1029/2007GL031277.

Rajeevan, M., S. Gadgil, and J. Bhate, 2010: Active and break spells of the Indian summer monsoon. J. Earth Syst. Sci., 119, 229247, https://doi.org/10.1007/s12040-010-0019-4.

Reynolds, R. W., T. M. Smith, C. Liu, D. B. Chelton, K. S. Casey, and M. G. Schlax, 2007: Daily high-resolution-blended analyses for sea surface temperature. J. Climate, 20, 5473-5496, https://doi.org/10.1175/2007JCLI1824.1.

Singh, C., 2013: Characteristics of monsoon breaks and intraseasonal oscillations over central India during the last half century. Atmos. Res., 128, 120-128, https://doi.org/10.1016/ j.atmosres.2013.03.003.

Ueda, H., and T. Yasunari, 1996: Maturing process of the summer monsoon over the western North Pacific: A coupled ocean/ atmosphere system. J. Meteor. Soc. Japan, 74, 493-508, https:// doi.org/10.2151/jmsj1965.74.4_493.

- _ _ - and R. Kawamura, 1995: Abrupt seasonal change of large-scale convective activity over the western Pacific in the northern summer. J. Meteor. Soc. Japan, 73, 795-809, https:// doi.org/10.2151/jmsj1965.73.4_795.

— M. Ohba, and S.-P. Xie, 2009: Important factors for the development of the Asian-northwest Pacific summer monsoon. J. Climate, 22, 649-669, https://doi.org/10.1175/2008JCLI2341.1.

Wilks, D. S., 2006: Statistical Methods in the Atmospheric Sciences. 2nd ed. Academic Press, 627 pp.

Wu, R., 2002: Processes for the northeastward advance of the summer monsoon over the western North Pacific. J. Meteor Soc. Japan, 80, 67-83, https://doi.org/10.2151/jmsj.80.67. 2010: Subseasonal variability during the South China Sea summer monsoon onset. Climate Dyn., 34, 629-642, https:/ doi.org/10.1007/s00382-009-0679-4.

— soon onset over the western North Pacific and the underlying processes. J. Climate, 13, 2483-2501, https://doi.org/10.1175/ 1520-0442(2000)013<2483:IVOSMO > 2.0.CO;2.

, and _ 2001: Multi-stage onset of the summer monsoon over the western North Pacific. Climate Dyn., 17, 277-289, https://doi.org/10.1007/s003820000118.

, B. P. Kirtman, and K. Pegion, 2008: Local rainfall-SST relationship on subseasonal time scales in satellite observations and CFS. Geophys. Res. Lett., 35, L22706, https://doi.org/ 10.1029/2008GL035883.

Wu, Z., and H. Lin, 2012: Interdecadal variability of the ENSONorth Atlantic Oscillation connection in boreal summer. Quart. J. Roy. Meteor. Soc., 138, 1668-1675, https://doi.org/ 10.1002/qj.1889.

_- B. Wang, J. Li, and F.-F. Jin, 2009: An empirical seasonal prediction model of the East Asian summer monsoon using ENSO and NAO. J. Geophys. Res., 114, D18120, https://doi org/10.1029/2009JD011733.

, J. Li, Z. Jiang, J. He, and X. Zhu, 2012: Possible effects of the North Atlantic Oscillation on the strengthening relationship between the East Asian summer monsoon and ENSO. Int. J. Climatol., 32, 794-800, https://doi.org/10.1002/joc.2309. 
Xu, K., and R. Lu, 2015: Break of the western North Pacific summer monsoon in early August. J. Climate, 28, 3420-3434, https://doi.org/10.1175/JCLI-D-14-00588.1.

Xu, Z. Q., K. Fan, and H. J. Wang, 2015: Decadal variation of summer precipitation over China and associated atmospheric circulation after the late 1990s. J. Climate, 28, 4086-4106, https://doi.org/10.1175/JCLI-D-14-00464.1.

Ye, K., and R. Wu, 2015: Contrast of local air-sea relationships between 10-20-day and 30-60-day intraseasonal oscillations during May-September over the South China Sea and western
North Pacific. Climate Dyn., 45, 3441-3459, https://doi.org/ 10.1007/s00382-015-2549-6.

Zhou, W., S.-P. Xie, and Z.-Q. Zhou, 2016: Slow preconditioning for the abrupt convective jump over the northwest Pacific during summer. J. Climate, 29, 8103-8113, https://doi.org/ 10.1175/JCLI-D-16-0342.1.

Zhu, Y., H. Liu, Y. Ding, F. Zhang, and W. Li, 2015: Interdecadal variation of spring snow depth over the Tibetan Plateau and its influence on summer rainfall over East China in the recent 30 years. Int. J. Climatol., 35, 3654-3660, https://doi.org/10.1002/joc.4239. 